\title{
RANCANG BANGUN APLIKASI PENGELOLAAN PINJAMAN KOPERASI BERBASIS MOBILE PADA KOPERASI PKK SEJAHTERA SUKABUMI
}

\author{
Ovi Sovia Maranti ${ }^{1}$, Lis Saumi Ramdhani ${ }^{2}$, Rusli Nugraha ${ }^{3}$, Khairul Rizal $^{4}$ \\ ${ }^{1}$ STMIK Nusa Mandiri Sukabumi \\ e-mail: soviaovi@gmail.com \\ ${ }^{2}$ AMIK BSI Sukabumi \\ e-mail: lis.lud@bsi.ac.id \\ ${ }^{3}$ AMIK BSI Sukabumi \\ e-mail: rusli.rng@bsi.ac.id \\ ${ }^{4}$ AMIK BSI Sukabumi \\ e-mail: khairul.krl@bsi.ac.id
}

\begin{abstract}
Abstrak
Koperasi adalah Suatu badan usaha yang beranggotakan dimana salah satu fungsinya yaitu sebagai gerakan ekonomi rakyat yang berdasar atas asas kekeluargaan. Namun Kebanyakan Koperasi simpan pinjam, yang sudah memiliki badan hukum, jumlah anggota yang cukup banyak itu mengakibatkan sistem pelaporan, pembukuan simpan pinjam dan pengajuan pinjaman menjadi kurang efektif, itu diakibatkan sistem yang digunakan masih menggunakan sistem konvensional, terutama dalam pengajuan pinjaman, hal ini yang mengakibatkan perputaran modal menjadi lambat. Untuk itu perlu upaya sebuah sistem yang berbasis mobile. Untuk pengelolaan pinjaman agar para anggota dapat mengajukan pinjaman yang lebih efektif. Penelitian ini dilakukan di Koperasi PKK Sejahtera Sukabumi pada pengajuan pinjaman dan pelaporan simpan pinjam, aplikasi mobile yang dibuat diintegrasikan dengan web server untuk memudahkan pengelolaan data dengan dibuat menggunakan bahasa PHP dan MySql serta model pengembangan perangkat lunak metode waterfall.Dengan sistem berbasis mobile, anggota dapat mengajukan pinjaman dari mana saja dan kapan saja, dan pengelolaan data untuk pengurus yang berbasis web diharapkan akan mempermudah pengelolaan sistem keuangan pada Koperasi.

Kata Kunci: Koperasi, Mobile, Pengajuan Pinjaman, Sistem Informasi
\end{abstract}

\begin{abstract}
Cooperative is a business entity consisting of a person or a cooperative, as well as a people's economic movement based on the principle of kinship. However, most savings and credit cooperatives, which already have legal entities, the large number of members resulted in the reporting system, savings and loan bookkeeping and loan application becomes less effective, it caused the system used still using conventional system, especially in the loan application, it is that resulting in slow turnover of capital. For that we need a mobile-based system. Android Mobile app technology one of the most widely used on Smartphone, has several advantages compared with the operating system on other mobile devices. This research was conducted at PKK Sejahtera Sukabumi Cooperative on loan application and reporting of savings and loan, mobile application that was made integrated with web server to facilitate data management by using PHP and MySql language and software development. With a mobile-based system, members can apply for loans from anywhere and anytime, and data management for webbased administrators is expected to facilitate the management of the financial system in the Cooperative.
\end{abstract}

Keywords: Cooperative, Mobile, Information System, Loan Application 


\section{Pendahuluan}

Teknologi memegang peran penting di era modernisasi seperti pada saat ini, dimana teknologi telah menjadi bagian yang tidak dapat dipisahkan dalam kehidupan sehari-hari. Perkembangan teknologi saat ini telah merambah ke segala aspek kehidupan sehingga saat ini seolah masyarakat telah dimanjakan oleh adanya alat-alat yang dapat memberikan kemudahan dalam aktifitas sehari-hari. Salah satunya adalah handphone, yang ditandai lahirnya teknologi Smartphone (Hati,dkk.2013). Smartphone pada saat ini menjadi kebutuhan yang wajib dimiliki oleh setiap orang untuk melakukan berbagai hal seperti komunikas, jejaring sosial, hiburan, sebagai media untuk mendapatkan dan mengolah data informasi. Teknologi aplikasi Mobile Android salah satu yang banyak digunakaan pada Smartphone, mempunyai beberapa kelebihan dibandingkan dengan sistem operasi pada perangkat seluler lainnya (Ibrohim dan hermawan.2016).

Berdasarkan IDC Research, Inc Market share pengguna sistem operasi mobile dapat dilihat pada gambar dibawah ini:

\begin{tabular}{|ccccc}
\hline Period & Android & ios & Windows Phone & Others \\
\hline 2016Q1 & $83.4 \%$ & $15.4 \%$ & $0.8 \%$ & $0.4 \%$ \\
\hline 2016Q2 & $87.6 \%$ & $11.7 \%$ & $0.4 \%$ & $0.3 \%$ \\
\hline 2016Q3 & $86.8 \%$ & $12.5 \%$ & $0.3 \%$ & $0.4 \%$ \\
\hline 2016Q4 & $81.4 \%$ & $18.2 \%$ & $0.2 \%$ & $0.2 \%$ \\
\hline $2017 Q 1$ & $85.0 \%$ & $14.7 \%$ & $0.1 \%$ & $0.1 \%$ \\
\hline
\end{tabular}

Gambar 1. Market share OS Mobile Sumber :IDC Mei 2017

Koperasi PKK Sejahtera Sukabumi merupakan koperasi simpan pinjam, yang sudah memiliki badan hukum, jumlah anggota yang cukup banyak itu mengakibatkan sistem pelaporan, pembukuan simpan pinjam dan pengajuan pinjaman menjadi kurang efektif, itu diakibatkan sistem yang digunakan masih menggunakan manual, terutama dalam pengajuan pinjaman, hal ini yang mengakibatkan kurang perputaran modal menjadi lambat, oleh karena itu perlu upaya sebuah sistem atau aplikasi yang terkomputerisasi, dimana anggota dapat mengajukan pinjaman dari mana saja dan kapan saja.

\section{Metode Penelitian}

Penelitian yang dilakukan oleh Dany Subiantara, Sulistiowati, dan Vivine Nurcahyawati (2015) tentang Rancang Bangun Aplikasi Simpan Pinjam Koperasi Karyawan Pada PT. Mega Utama Indah berbasis desktop dengan menggunakan Visual Studio 2010 dan MySQL.

Penelitian oleh Hayyu Natta Atikah, Sukardi (2014) tentang Sistem Simpan Pinjam Pada Koperasi Pegawai Republik Indonesia (KPRI) Dwija Karya Kecamatan Tulakan. Sistem simpan pinjam yang dibuat menggunakan bahasa PHP dan MySql.

Dalam upaya pengumpulan data untuk penelitian ini menggunakan tiga macam metode, yaitu:

1. Observasi

Metode ini dilakukan dengan cara pengamatan langsung ketempat dalam hal ini Koperasi PKK Sejahtera Sukabumi untuk mengamati sistemnya.

2. Wawancara

Metode ini dilakukan untuk memperoleh informasi dan data dari objek yang diteliti dalam hal ini yang menjadi objek wawancara adalah bagian ketua koperasi.

3. Studi Pustaka

Metode studi pustaka dilakukan dengan cara mencari data dari sumber bukubuku, makalah-makalah, jurnal, $e$ journal, website dan lain sebagainya yang berhubungan dengan pelaporan Berita Acara dan permasalahan yang dibahas.

Untuk model pengembangan perangkat lunak menggunakan metode waterfall. Beberapa tahapan pengembangan sistem pada penelitian ini yaitu:

\section{Analisa Kebutuhan Software}

Langkah ini merupakan tahap pengumpulan data, analisa interface guna menentukan solusi dari perangkat lunak yang diperlukan yang nantinya akan digunakan sebagai proses komputerisasi sistem.
2. Desain
Proses Desain terbagi kedalam beberapa bagian desain yakni desain database, desain sistem dan desain interface. Pada skripsi ini software yang 
digunakan untuk mendesain database adalah mysql adapula software Android Studio dan Dreamweaver yang digunakan sebagai tool untuk merancang interface dari sistem yang akan dibuat.

3. Code Generation

Proses pembuatan coding atau pengkodean merupakan penterjemahan desain kedalam bahasa yang bisa dikenali oleh komputer yang akan menterjemahkan permintaan user ke sebuah software, dalam skripsi ini bahasa pemrograman yang digunakan adalah mobile,php,html.

4. Testing

Proses mememukan kesalahan terhadap sistem yang telah diimplementasikan kedalam sebuah software, pada skripsi ini teknik pengujian yang akan dilakukan adalah teknik blackbox testing.

5. Support

Setelah melakukan analisis, desain dan pengkodean maka sistem sudah jadi akan digunakan user, maka dari itu support dari pengembang masih perlu dilakukan untuk pemeriksaan secara berkala.

\section{Hasil dan Pembahasan}

Penelitian ini dilakukan di Koperasi PKK Sejahtera Sukabumi pada pengajuan pinjaman dan pelaporan simpan pinjam, aplikasi mobile yang dibuat diintegrasikan dengan web server untuk memudahkan pengelolaan datanya.

\subsection{Use Case Diagram}

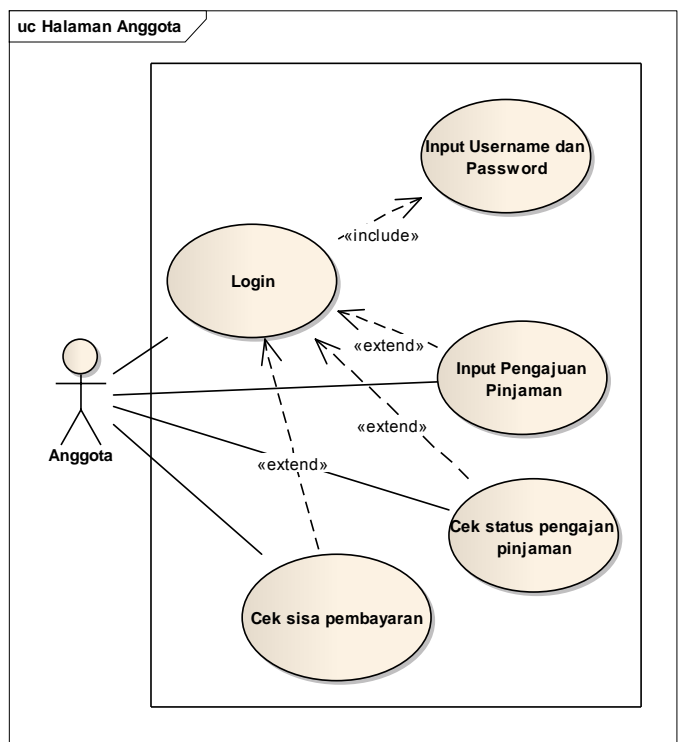

Gambar 2. Use Case Diagram Pengajuan Pinjaman Halaman Anggota

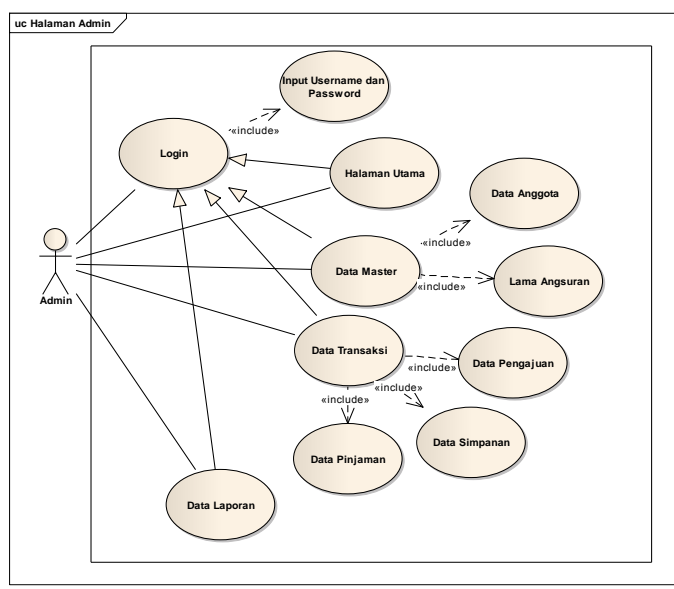

Gambar 3. Use Case Diagram Pengajuan Pinjaman Halaman Admin

\subsection{Entity Relationship Diagram}

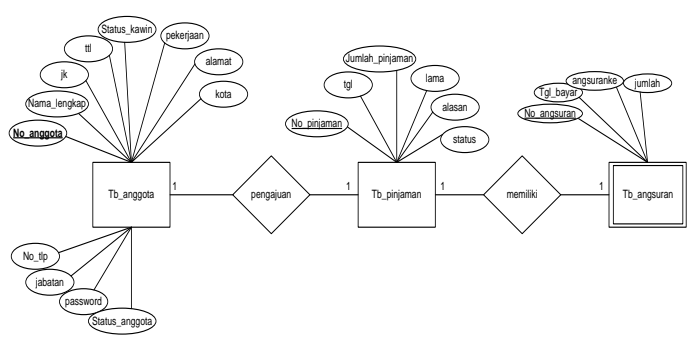

Gambar 4. Entity Relationshop Diagram Pengajuan Pinjaman

\subsection{Spesifikasi File}

$\begin{array}{ll}\text { Spesifikasi File Tabel Anggota } \\ \text { Nama Database } & : \text { db_koperasi } \\ \text { Nama File } & : \text { Tabel Anggota } \\ \text { Akronim } & : \text { tb_anggota.myd } \\ \text { Tipe File } & : \text { File Master } \\ \text { Akses File } & : \text { Random } \\ \text { Panjang Record } & : \text { 470 Byte } \\ \text { Kunci Field } & : \text { no_anggota }\end{array}$

Tabel 1. Spesifikasi File Tabel Anggota

\begin{tabular}{|c|l|l|c|c|}
\hline No & Nama Field & Type & Size & $\begin{array}{c}\text { Keteran } \\
\text { gan }\end{array}$ \\
\hline 1 & No_anggota & Varchar & 20 & $\begin{array}{c}\text { Primary } \\
\text { Key }\end{array}$ \\
\hline 2 & $\begin{array}{l}\text { Nama_lengk } \\
\text { ap }\end{array}$ & Varchar & 10 & \\
\hline 3 & $\mathrm{jk}$ & Varchar & 10 & \\
\hline 4 & $\mathrm{ttl}$ & Varchar & 20 & \\
\hline 5 & $\begin{array}{l}\text { Status_kawi } \\
\mathrm{n}\end{array}$ & Varchar & 10 & \\
\hline 6 & Pekerjaan & Varchar & 30 & \\
\hline 7 & alamat & Text & - & \\
\hline \multicolumn{4}{|l}{} &
\end{tabular}




\begin{tabular}{|c|l|l|c|l|}
\hline 8 & Kota & Varchar & 20 & \\
\hline 9 & No_tlp & Varchar & 20 & \\
\hline 10 & Jabatan & Varchar & 10 & \\
\hline 11 & Password & Varchar & 50 & \\
\hline 12 & $\begin{array}{l}\text { Status_angg } \\
\text { ota }\end{array}$ & Varchar & 20 & \\
\hline
\end{tabular}

\subsection{User Interface}

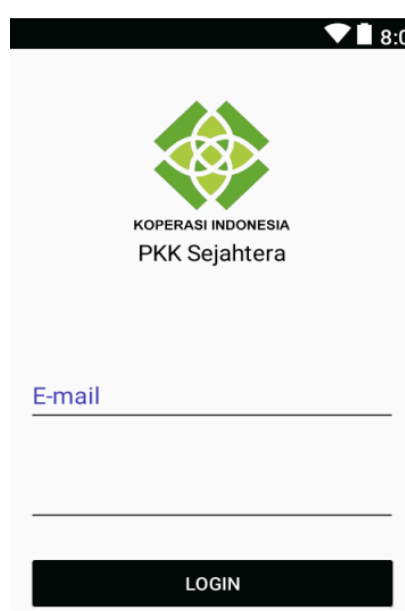

\section{Spesifikasi File Tabel Pinjaman}

$\begin{array}{ll}\text { Nama Database } & \text { :db_Koperasi } \\ \text { Nama File } & : \text { Tabel Pinjaman } \\ \text { Akronim } & \text { :tb_pinjaman.myd } \\ \text { Tipe File } & : \text { File Transaksi } \\ \text { Akses File } & : \text { Random } \\ \text { Panjang Record } & : 111 \text { Byte } \\ \text { Kunci Field } & : \text { No_pinjaman }\end{array}$

Tabel 2. Spesifikasi File Tabel Pinjaman

\begin{tabular}{|c|c|c|c|c|}
\hline No & Nama Field & Type & Size & $\begin{array}{c}\text { Ketera } \\
\text { ngan }\end{array}$ \\
\hline 1 & No_pinjaman & Varchar & 10 & $\begin{array}{c}\text { Primar } \\
\text { y Key }\end{array}$ \\
\hline 2 & $\mathrm{Tgl}$ & Varchar & 10 & \\
\hline 3 & $\begin{array}{l}\text { Jumlah_pinja } \\
\text { man }\end{array}$ & Int & 11 & \\
\hline 4 & Lama & Varchar & 30 & \\
\hline 5 & Alasan & Varchar & 20 & \\
\hline 6 & Status & Varchar & 10 & \\
\hline 7 & No_anggota & Varchar & 20 & $\begin{array}{l}\text { Foreig } \\
\text { n Key }\end{array}$ \\
\hline
\end{tabular}

\section{Spesifikasi File Tabel Angsuran}

$\begin{array}{ll}\text { Nama Database } & \text { :db_Koperasi } \\ \text { Nama File } & : \text { Tabel Angsuran } \\ \text { Akronim } & : \text { tb_angsuran.myd } \\ \text { Tipe File } & : \text { File Transaksi } \\ \text { Akses File } & : \text { Random } \\ \text { Panjang Record } & : \text { : } 70 \text { Byte } \\ \text { Kunci Field } & : \text { No_angsuran }\end{array}$

Tabel 3. Spesifikasi File Tabel Angsuran

\begin{tabular}{|c|l|l|c|c|}
\hline $\begin{array}{c}\mathrm{N} \\
0\end{array}$ & Nama Field & Type & Size & $\begin{array}{c}\text { Keterang } \\
\text { an }\end{array}$ \\
\hline 1 & No_angsuran & Varchar & 10 & $\begin{array}{c}\text { Primary } \\
\text { Key }\end{array}$ \\
\hline 2 & Tgl_bayar & Varchar & 10 & \\
\hline 3 & angsuranke & Int & 10 & \\
\hline 4 & jumlah & Varchar & 30 & \\
\hline 5 & No_pinjaman & Varchar & 10 & $\begin{array}{l}\text { Foreign } \\
\text { Key }\end{array}$ \\
\hline
\end{tabular}

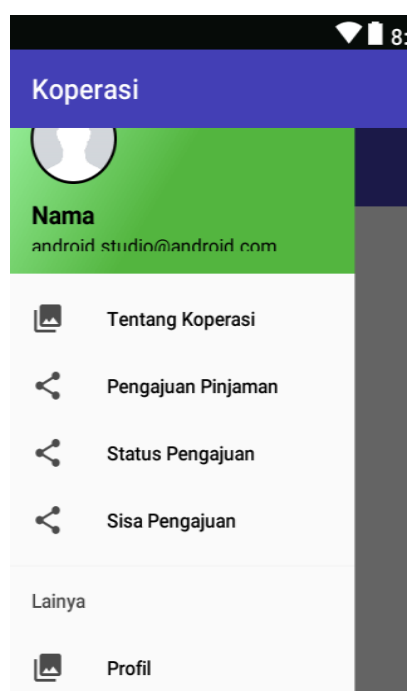

Gambar 6. Halaman Beranda Anggota

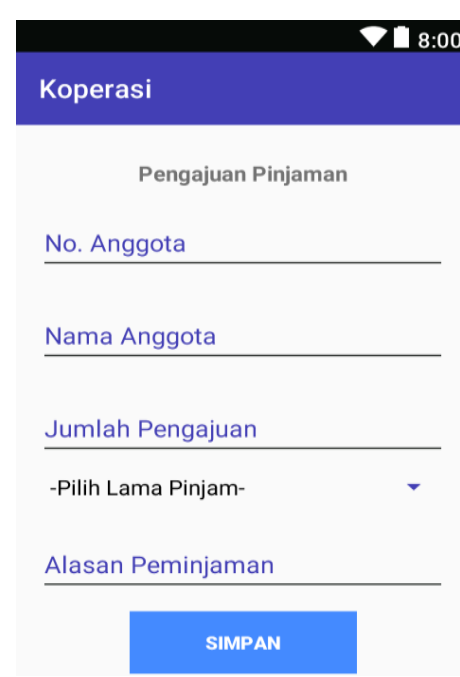


Gambar 7. Halaman Pengajuan

Pinjaman Anggota

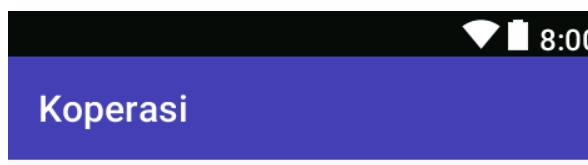

Sisa Pinjaman

No. Anggota : AG001

Nama Anggota : Uji Coba

Jumlah Pinjaman : Rp. 300.000

Sisa Angsuran : 1 Kali

Sisa Pinjaman : Rp. 300.000

\section{KEMBALI}

Gambar 8. Halaman Sisa Pinjaman Anggota

KOPERASI PKK SEJAHTERA

\section{No. Anggota}

Password

\section{LOGIN}

Gambar 9. Halaman Login Admin

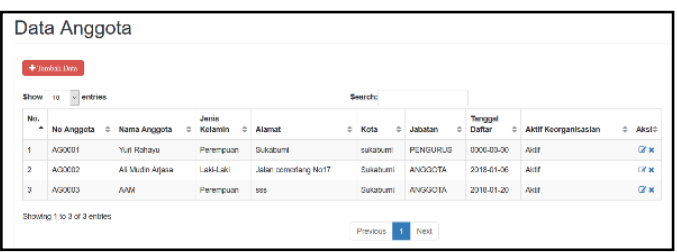

Gambar 10. Halaman Form Anggota

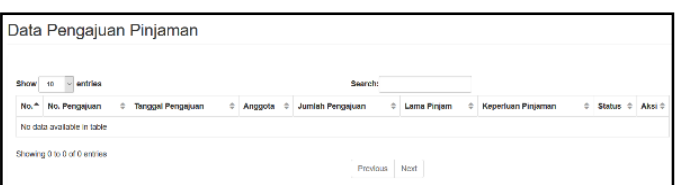

Gambar 11. Halaman Form Pengajuan Pinjaman

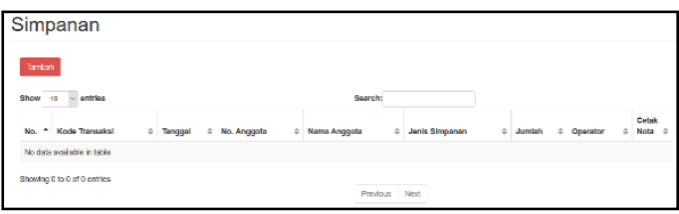

Gambar 12. Halaman Form Data Simpanan

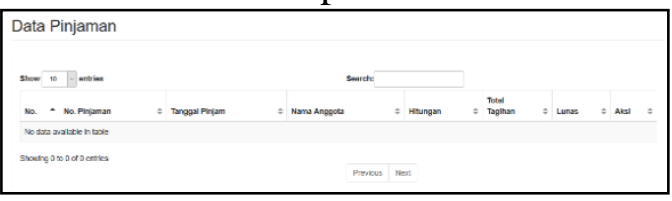

Gambar 13. Halaman Form Data Pinjaman

\section{Kesimpulan}

Dengan penerapan aplikasi mobile dalam pengajuan pinjaman akan memudahkan anggota dalam pengajuan pinjaman tanpa harus datang ke bendahara koperasi. Dan dengan adanya sistem yang berbasis web dalam pengelolaan simpan pinjamannya, maka laporan bulanan akan lebih mudah dibuatkan oleh bagian bendahara.

\section{Referensi}

Anhar. 2010. Panduan Menguasai PHP \& MySQL secara Otodidak. Jakarta: MediaKita.

Atikah, Sukardi (2014) Sistem Informasi Simpan Pinjam Pada Kperasi Pegawai Republik Indonesia (KPRI) Dwiza Karya Kecamatan Tulakan. (Jurnal Speed-Sentra Penelitian Engineering dan Edukasi-Vol 6 No. $12014)$.

Gunawan, Wahyu. 2010. Kebut Sehari Jadi Webmaster. Yogyakarta : Genius Publisher.

Chumairoh, et al (2014). Perancang Bangun Aplikasi Mobile Pada Platform Android Berbasis Html5 Studi Kasus Layanan Informasi Website Unipdu Jombang. ISSN 2407-4489. Jurnal IImiah Edutic /Vol.1, No.1, Nopember 2014.

Hati, Gunita Mustika, dkk.2013. Aplikasi Penanda Lokasi Peta Digital Berbasis Mobile Gispada Smartphone Android.ISSN: 2337845X. Jurnal Geodesi Undip. Volume 2, Nomor 4.

Ibrohim dan hermawan.2016. Pengembangan Sistem Informasi Akademik Universitas Serang 
Raya (Infosera) Berbasis Mobile Android. ISSN: 2406-7768. Jurnal Sistem Informasi Volume.3.

Madcoms. 2011. Aplikasi Web Database dengan Dreamweaver dan PHP MySQL. Yogyakarta : CV Andi Offset.

Madcoms. 2012. JavaScript untuk membangun Website Profesional. Yogyakarta: CV Andi Offset.

Mulyanto, Agus. 2009. Sistem Informasi Konsep \& Aplikasi. Yogyakarta: Pustaka Pelajar.

Puspitosari, A. Heni. 2010. Membangun Website Interaktif dengan Adobe Creative Suite 5. Yogyakarta: PT. Skripta Media Creative.

Rosa, A.S. dan M. Shalahuddin. 2014. Rekayasa Perangkat Lunak Terstruktur dan Berorientasi Objek. Bandung : Informatika.

Simarmata. Janner. 2010. Rekayasa Perangkat Lunak. Yogyakarta: Andi.

Sommerville, lan. , 2011. Software Engineering (Software Engineering Software). New York:McGraw

Sobri dan Abdillah (2013). Aplikasi Belajar Membaca Iqro' Berbasis Mobile. ISSN: 2302 -2805. Seminar Nasional Teknologi Informasi dan Multimedia 2013. STMIK AMIKOM Yogyakarta, 19 Januari 2013.

Subiantara, Dany, Sulistiowati, \& Nurcahyawati, Vivine ( 2015) Rancang Bangun Aplikasi Simpan Pinjam Koperasi Pada PT. Mega Utama Indah. JSIKA. Vol. 4 No.2, September 2015. Diambil dari: http ://jurnal.stikom. edu/index.php/jsika /article/ view/890

Utomo, Eko Priyato, dan Ali Akbar. 2012. 1 Menit bikin Web Sendiri dengan PHP dan JQuery. Yogyakarta: Mediakom. 